\title{
Posterior retroperitoneoscopic approach to the adrenal arteries
}

\author{
Marco Lotti ${ }^{1}$ (1) Michela Giulii Capponi ${ }^{1}$
}

Received: 9 February 2016/Accepted: 15 March 2016/Published online: 8 April 2016

(C) Springer Science+Business Media New York 2016

\begin{abstract}
Background Differently from transperitoneal adrenalectomy, with the posterior retroperitoneoscopic approach adrenal arteries are dissected first [1,2]. Knowledge of their position is pivotal as they are covered by peri-adrenal fat $[3,4]$.

Methods Four posterior retroperitoneoscopic adrenalectomies were selected, in which adrenal arteries are dissected to show their path and how they can be localized among peri-adrenal fat.

Results A video is presented herein, which focuses on surgical anatomy of adrenal arteries when approached during a posterior retroperitoneoscopic adrenalectomy. Details about relative positions between adrenal arteries and adjacent structures are considered and shown during their dissection.

Conclusions The posterior retroperitoneoscopic approach offers a direct view of adrenal arteries and allows for their exposure and safe division in the early steps of adrenalectomy.
\end{abstract}

Keywords Posterior retroperitoneoscopic adrenalectomy · Laparoscopic adrenalectomy ·
Adrenalectomy $\cdot$ Suprarenal $\cdot$ Anatomy adrenal $\cdot$ Adrenal vein

\section{Compliance with ethical standards}

Disclosures Marco Lotti, and Michela Giulii Capponi have no conflicts of interest or financial ties to disclose.

\section{References}

1. Walz MK, Alesina PF, Wenger FA, Deligiannis A, Szuczik E, Petersenn S, Ommer A, Groeben H, Peitgen K, Janssen OE, Philipp T, Neumann HP, Schmid KW, Mann K (2006) Posterior retroperitoneoscopic adrenalectomy-results of 560 procedures in 520 patients. Surgery 140(6):943-948

2. Zhang X, Fu B, Lang B, Zhang J, Xu K, Li HZ, Ma X, Zheng T (2007) Technique of anatomical retroperitoneoscopic adrenalectomy with report of 800 cases. J Urol 177(4):1254-1257

3. Budhiraja V, Rastogi R, Asthana AK (2010) Renal artery variations: embryological basis and surgical correlation. Rom J Morphol Embryol 51(3):533-536

4. Dutta S (2010) Suprarenal gland-arterial supply: an embryological basis and applied importance. Rom J Morphol Embryol 51(1):137-140
Electronic supplementary material The online version of this article (doi:10.1007/s00464-016-4884-z) contains supplementary material, which is available to authorized users.

\section{Marco Lotti}

im.marco.lotti@gmail.com

1 Advanced Surgical Oncology Unit, Department of General Surgery 1, Papa Giovanni XXIII Hospital, Piazza OMS, 1, 24127 Bergamo, Italy 